\title{
Sp1 mediates phorbol ester (PMA)-induced expression of membrane-bound guanylyl cyclase GC-A in human monocytic THP-1 cells*
}

\author{
Małgorzata Mitkiewicz ${ }^{1 凶}$, Bernadeta Bac², Marianna Kuropatwa1, Ewa Kurowska1, \\ Janusz Matuszyk ${ }^{1}$ and Jakub Siednienko ${ }^{1,3}$
}

1 Laboratory of Signal Transduction Molecules, Ludwik Hirszfeld Institute of Immunology and Experimental Therapy, Polish Academy of Sciences, Wrocław, Poland; 2 Department of Chemistry, Wrocław University of Science and Technology, Wrocław, Poland; ${ }^{3}$ Nanobioengineering Laboratory, Wrocław Research Centre EIT+, Wrocław, Poland

\begin{abstract}
Cyclic guanosine monophosphate (cGMP) is synthesized by two types of enzymes: particulate (membrane-bound) guanylyl cyclases (pGCs) and soluble (cytosolic) guanylyl cyclases (sGCs). sGCs are primarily activated by binding of nitric oxide to their prosthetic heme group while pGCs are activated by binding of peptide ligands to their extracellular domains. One of them, pGC type A (GC-A) is activated by atrial and brain natriuretic peptides (ANP and BNP, respectively). Human monocytes isolated from peripheral blood mononuclear cells have been found to display SGC expression without concomitant expression of GC-A. However, GC-A activity appears in monocytes under certain conditions but a molecular mechanism of GC-A expression is still poorly understood. In this report we show that phorbol ester (PMA) induces transcription of a gene encoding GC-A in human monocytic THP1 cells. Moreover, we find that PMA-treated THP-1 cells raise cGMP content following treatment with ANP. Studies using pharmacological inhibitors of protein kinases suggest involvement of protein kinase $C(P K C)$, mitogen extracellular kinases (MEK1/2), and extracellular signalregulated kinases (ERK1/2) in PMA-induced expression of the GC-A encoding gene in THP-1 cells. Finally, we show that PMA stimulates binding of Sp1 transcription factor to GC-rich DNA sequences and mithramycin A (a selective Sp1 inhibitor) inhibits expression of the GC-A mRNA in PMA-treated THP-1 cells. Taken together, our findings suggest that the PMA-stimulated PKC and MEK/ERK signaling pathways induce Sp1-mediated transcription of the GC-A encoding gene in human monocytic THP-1 cells.
\end{abstract}

Key words: membrane-bound guanylyl cyclase type A, phorbol 12-myristate 13-acetate, human monocytic cell line THP-1, protein kinases, Sp1 transcription factor

Received: 18 October, 2017; revised: 09 June, 2018; accepted: 18 June, 2018; available on-line: 30 June, 2018

e-mail: ciuman@iitd.pan.wroc.pl

*Preliminary report: These results were presented at the 1st Congress of Polish Biochemistry, Cell Biology, Biophysics and Bioinformatics (BIO 2014), Warsaw, Poland (9-12 September, 2014).

Abbreviations: ANP, atrial natriuretic peptide; cGMP, cyclic guanosine monophosphate; ERK 1/2, extracellular signal-regulated kinases; GC-A, membrane-bound guanylyl cyclase type A; MEK 1/2, mitogen extracellular kinases; PKC, protein kinase C; PMA, phorbol 12-myristate 13-acetate; sGC, soluble guanylyl cyclase; Sp1, specificity protein 1

\section{INTRODUCTION}

Guanylyl cyclase type A (GC-A) belongs to a family of particulate guanylyl cyclases (pGCs) which similarly to the soluble guanylyl cyclases (sGCs) catalyze synthesis of a common secondary messenger, namely cyclic GMP (cGMP), involved in many cellular processes (Pilz \& Casteel, 2003; Potter et al., 2006). Although both forms of GCs produce the same secondary messenger, activation of each of them triggers different signaling pathways leading to different cellular effects (Zolle et al., 2000; Su et al., 2005; Mitkiewicz et al., 2011). This indicates that the final effect of cGMP depends on the site of its synthesis in the cell (cytosol or cell membrane). GC-A is a single membrane spanning receptor activated by binding of atrial natriuretic peptide (ANP) or brain natriuretic peptide (BNP) to the extracellular domain of the enzyme. The widespread expression of GC-A in different cell types and tissues (Potter et al., 2006) suggests that this protein may regulate many cellular processes. The role of ANP and GC-A in the cardiovascular system is well documented. It has been shown that the ANP/GC-A system is implicated in reducing cardiac output, stimulation of natriuresis, diuresis, vasorelaxation and inhibition of the renin-angiotensin-aldosterone pathway (Pandey 2011; Potter et al., 2006). The available data suggest that GC-A also regulates inflammatory reactions. Reports demonstrate anti-inflammatory action of this enzyme. It was found that the ANP-triggered GC-A/ cGMP-signaling pathway decreases activity of AP-1 and $\mathrm{NF}-\kappa \mathrm{B}$ transcription factors in activated myeloid cells and thus suppresses release of inflammatory cytokines (IL-1 $\beta$, IL-6, TNF $\alpha$ ) and inhibits expression of inducible nitric oxide synthase (Kiemer et al., 2000; Mitkiewicz et al., 2011; Mezzasoma et al., 2016). The anti-inflammatory action of ANP was shown to also occur in mice treated with LPS (Ladetzki-Baehs et al., 2007; Nojiri et al., 2014).

In a human monocyte subset purified from peripheral blood mononuclear cells (PBMCs) the sGC activity was predominately detected (Bender et al., 2004). It was shown that human monocytes do not express GC-A, but monocyte-derived dendritic cells do express functional GC-A (Morita et al., 2003). Moreover, Bender and coworkers (Bender et al., 2004) stimulated differentiation of human monocytes and found that GM-CSF differentiated macrophages, but not primary monocytes, express GC-A mRNA. However, the molecular mechanism of GC-A expression in monocytes/macrophages remains unclear. 
Taking into account the fact that in some pathological conditions (i.e. in hypertension, heart failure, and cirrhosis) concentrations of GC-A ligands (ANP and BNP) in the blood plasma of patients were increased (Licata et al., 2013; Szabó et al., 2013), one can assume that concomitant increase in the GC-A expression may be significant in the development of these diseases. Therefore, it appears that a better understanding of the mechanisms responsible for the activation of the GC-A gene in monocytes/macrophages may be the basis for the development of a therapy for patients with chronically elevated levels of natriuretic peptides.

In this study, signaling pathway involved in the PMAinduced GC-A gene expression in the monocytic cell line was investigated and our findings show that the PMAinduced GC-A gene expression requires DNA-binding activity of the Sp1 transcription factor.

\section{MATERIALS AND METHODS}

Reagents. RPMI 1640 and Dulbecco's PBS were from Cytogen (Sinn, Germany). Fetal calf serum was from Thermo Scientific HyClone (Cramlington, UK). ANP was obtained from Calbiochem (La Jolla, USA). Antibiotics, IBMX, PMA, U0126, FR180204, and mithramycin A were purchased from Sigma-Aldrich (St. Louis, USA). Ro 31-8220 was obtained from Merck Millipore (Darmstadt, Germany). Anti-GC-A antibody was from LifeSpan Biosciences (Seattle, USA). IRDye 800CW goat anti-rabbit IgG secondary antibody conjugate was from LI-COR Biosciences (Lincoln, USA).

Cell culture. Human monocytic cell line (THP-1) was obtained from European Collection of Authenticated Cell Cultures (ECACC). THP-1 cells were propagated in RPMI 1640 medium, supplemented with 10\% fetal calf serum, $1 \mathrm{mM}$ sodium pyruvate, and with antibiotics (100 $\mathrm{U} / \mathrm{ml}$ penicillin $\mathrm{G}, 0.25 \mu \mathrm{g} / \mathrm{ml}$ amphotericin $\mathrm{B}, 0.1 \mathrm{mg} /$ $\mathrm{ml}$ streptomycin), at $37^{\circ} \mathrm{C}$ in $5 \% \mathrm{CO}_{2}$. THP-1 monocytes were differentiated into macrophages by treatment with $500 \mathrm{nM}$ PMA for $3 \mathrm{~h}$ at $37^{\circ} \mathrm{C}$. Then, the cells were centrifuged at $400 \times g$ for $5 \mathrm{~min}$ at $20^{\circ} \mathrm{C}$, resuspended in culture medium, seeded in plates, and incubated at $37^{\circ} \mathrm{C}$, $5 \% \mathrm{CO}_{2}$ for $72 \mathrm{~h}$. In some experiments, THP-1 cells were treated with specific inhibitors $(1 \mu \mathrm{M}$ Ro 31-8220, $10 \mu \mathrm{M}$ U0126, $50 \mu \mathrm{M}$ FR180204 or $200 \mathrm{nM}$ mithramycin A) for 45 min before stimulation with PMA. Cell viability in response to inhibitors was determined by Trypan Blue exclusion and was found not to be adversely affected.

Induction and measurement of intracellular cGMP. Control and PMA-treated cells $\left(0.5 \times 10^{6}\right.$ cells per well/24-well plate) were supplemented with a non-specific inhibitor of phosphodiesterases $(0.5 \mathrm{mM}$ IBMX) to prevent hydrolysis of the synthesized cGMP. Cells were incubated for $10 \mathrm{~min}$ at $37^{\circ} \mathrm{C}$ and then GC-A activator $(0.1 \mu \mathrm{M}$ ANP) was added. After $30 \mathrm{~min}$ incubation, the reaction was terminated, the cells were disintegrated and intracellular concentration of cGMP was determined using an immunoenzymatic assay (ELISA) based on rabbit polyclonal antibodies highly specific to cGMP (Kobiałka et al., 2003).

Western blotting. THP-1 cells (control and PMA-treated; $1 \times 10^{6}$ cells per well/6-well plate) were lysed in high salt lysis buffer (50 mM HEPES pH 7.5, $150 \mathrm{mM} \mathrm{NaCl}, 2 \mathrm{mM}$ EDTA, 1\% NP-40, 0.5\% sodium deoxycholate, $0.8 \mathrm{mM}$ PMSF, protease inhibitor cocktail, $5 \% \beta$-mercaptoethanol, and 1xLaemmli sample buffer) on ice for $20 \mathrm{~min}$. Whole cell lysates were then incu- bated at $99^{\circ} \mathrm{C}$ for $10 \mathrm{~min}$ and subjected to $12 \%$ SDSPAGE. Next, the proteins were electrotransferred onto nitrocellulose membranes, blocked with $2 \%$ casein for $2 \mathrm{~h}$, and then incubated overnight with anti-GC-A antibodies. After washing, the membranes were incubated with IRDye $800 \mathrm{CW}$ goat anti-rabbit IgG secondary antibody conjugate for $1 \mathrm{~h}$. Immunoreactivities were determined using the Odyssey Infrared Imaging System (LICOR Biosciences, USA).

Quantitative PCR (qPCR). Total RNA was extracted from cells $\left(1 \times 10^{6}\right.$ cells per well/6-well plate) using ReliaPrep ${ }^{\mathrm{TM}}$ RNA Cell System, and cDNA was synthesized using M-MLV reverse transcriptase, according to the manufacturer's instructions (Promega, USA). cDNA was subjected to qPCR with GoTaq qPCR Master Mix with BRYT Green dye (Promega, USA) in a real-time PCR system (CFX Connect Real-time System, Bio-Rad, USA). For mRNA quantification, hypoxanthine phosphoribosyltransferase 1 (HPRT) housekeeping gene was used as a reference point. The sequences of primers used for qPCR were as follows: GC-A, 5'-ATGGTGCCTTCGGGGT'TGTACTGA-3' (forward) and 5'-AAGGTGATCT'TGGT'TGCATGCTGG-3' (reverse); HPRT, 5'-AGCT'TGCTGGTGAAAAGGAC-3' (forward) and 5'-T'TATAGTCAAGGGCATATCC-3' (reverse). qPCR data were analyzed using the $2^{-\Delta \Delta \mathrm{Ct}}$ method (Livak \& Schmittgen, 2001).

Nuclear extract and electrophoretic mobility shift assay (EMSA). Cells (control and PMA-treated, $1 \times 10^{6}$ cells per well/6-well plate) were washed with ice-cold PBS and disintegrated in ice-cold buffer A $(10 \mathrm{mM}$

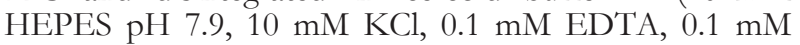
EGTA, $1 \mathrm{mM}$ DTT, $1 \mathrm{mM}$ PMSF, $0.1 \mathrm{mM}$ sodium orthovanadate, $0.1 \% \mathrm{NP}-40$ ) on ice for $15 \mathrm{~min}$. After centrifugation at $12000 \times g$ for $1 \mathrm{~min}$ at $4^{\circ} \mathrm{C}$, the supernatants were removed and the nuclear pellets were resuspended in $3 \times$ the packed nuclear volume of ice-cold high-salt buffer B (20 mM HEPES pH 7.9, 10 mM KCl, $1 \mathrm{mM}$ EDTA, $1 \mathrm{mM}$ EGTA, $420 \mathrm{mM} \mathrm{NaCl}, 20 \%$ glycerol, $1 \mathrm{mM}$ DTT, $1 \mathrm{mM}$ PMSF). The samples were gently vortexed at $4^{\circ} \mathrm{C}$ for $30 \mathrm{~min}$, centrifuged at $12000 \times \mathrm{g}$ for $10 \mathrm{~min}$ at $4^{\circ} \mathrm{C}$, and the supernatants (the nuclear extracts) were saved. Nuclear extracts $(10 \mu \mathrm{g}$ of protein) were incubated with $50 \mathrm{fmol}$ of a double-stranded oligonucleotide 5'-AT'TCGATCGGGGCGGGGCGAGC-3' containing the Sp1 consensus-binding site and end-labeled with IRDye 700 infrared dye according to the manufacturer's protocol (Odyssey EMSA Buffer Kit, LICOR Biosciences, USA). Electrophoretic mobility shift assay was performed in a $5 \%$ native polyacrylamide gel in TBE buffer $(0.5 \times)$. The Sp1-DNA complexes were then analysed using Odyssey Infrared Imaging System (LI-COR Biosciences, USA).

Statistical analysis. Data are presented as the means \pm S.E. of the values obtained from at least three independent experiments. Statistical analysis was carried out using the unpaired Student's $t$-test assuming $p<0.05$ to be statistically significant.

\section{RESULTS}

\section{PMA induces expression of the GC-A gene in THP-1 cells}

The effect of PMA on GC-A expression was determined by qPCR. It was observed that GC-A mRNA expression was significantly increased in THP-1 cells treated with PMA (Fig. 1A). GC-A expression was confirmed 


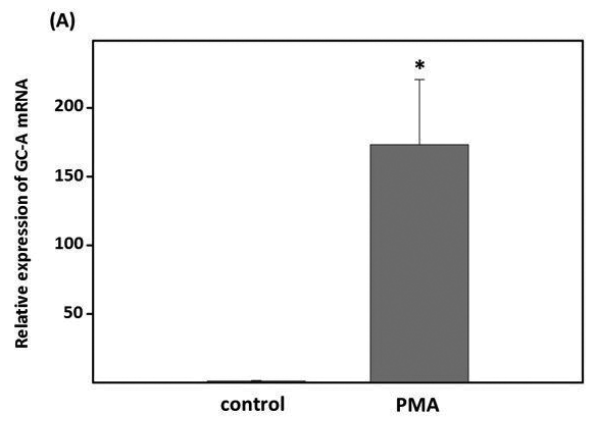

(B)

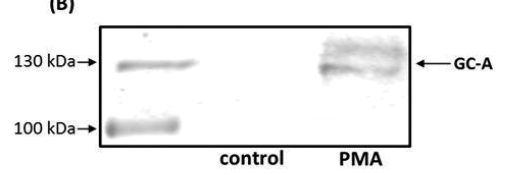

(C)

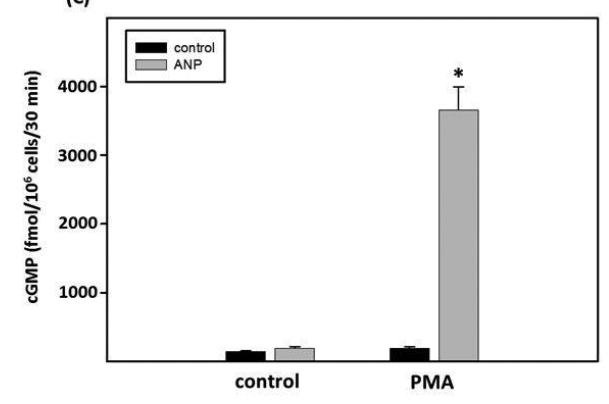

Figure 1. Expression of GC-A appears in PMA-treated THP-1 cells.

(A) Total RNA was isolated from the control and PMA-treated cells and the GC-A gene expression was determined using qPCR and was normalized to HPRT. (B) Cells were lysed and samples were subjected to SDS-PAGE; Western blotting was performed using an anti-GC-A antibody. (C) Cells were treated with $0.1 \mu M$ ANP (GC$A$ activator) for $30 \mathrm{~min}$ in the presence of PDE inhibitor $(0.5 \mathrm{mM}$ IBMX). Then, intracellular CGMP was determined using ELISA. ${ }^{*} p<0.001$ versus control cells.

at the protein level using Western blotting. Anti-GC-A antibody recognized a $130-\mathrm{kDa}$ band, corresponding to the molecular mass of GC-A, in extracts of PMA-treated cells but not in the control cells (Fig. 1B). Finally, an increased production of cGMP in PMA-treated cells was detected by ELISA. As shown in Fig. 1C, the level of cGMP produced by PMA-treated cells in response to ANP was about 20-fold higher (3660 $332 \mathrm{fmol} / 10^{6}$ cells) than in the control cells $\left(190 \pm 27 \mathrm{fmol} / 10^{6}\right.$ cells $)$.

\section{PKC is involved in activation of the GC-A gene}

Because PMA is known to activate protein kinase $\mathrm{C}$ (PKC), PKC is thought to mediate PMA-induced effects. Therefore, we checked whether this protein kinase is involved in regulation of the GC-A gene expression in PMA-treated THP-1 cells. As shown by qPCR, the GC-A gene expression in PMA-treated cells was significantly reduced in the presence of Ro 318220, a selective PKC inhibitor (Fig. 2A). This result is consistent with the data obtained from an ELISA assay showing that Ro 31-8220 caused about 45\% reduction in ANP-triggered cGMP accumulation in PMA-treated cells (Fig. 2B). The obtained results suggest that PKC mediates PMA-induced expression of the GC-A gene in THP-1 cells.

\section{MEK1/2 and ERK1/2 are engaged in PMA-induced expression of the GC-A gene}

It is well known that PKC activates the MAP kinase pathway. Therefore, we examined whether MEK1/2 (mitogen extracellular kinases) and ERK1/2 (extracellular signal-regulated kinases) are required for the PMA-induced expression of the GC-A gene in THP-1 cells. Involvement of MEK1/2 and ERK1/2 in this process was tested using specific protein kinase inhibitors: U0126 in the case of MEK1/2, and FR180204 in the case of ERK1/2. As shown in the Fig. 3A, the PMA-induced GC-A expression was markedly decreased in the presence of MEK $1 / 2$ inhibitor. U0126 also caused an almost complete inhibition of the GC-A activity. It was observed that the detected level of ANP-triggered total cellular cGMP accumulation was reduced from $3534 \pm 396 \mathrm{fmol} / 10^{6}$ cells in PMAtreated cells to $379 \pm 29 \mathrm{fmol} / 10^{6}$ cells in cells preincubated with U0126 (Fig. 3B). The stimulatory effect of PMA was also reduced by FR180204. However, the use of this inhibitor resulted in a significantly weaker inhibition of the GC-A gene expression (Fig. 3A) and did not affect accumulation of cGMP in PMA-treated cells (Fig. 3B). Because U0126 inhibits activation of ERK1/2 by inhibiting the kinase activity of MEK1/2, the obtained results suggest that activation of MEK/ ERK-signaling cassette is essential for the PMA-induced GC-A expression.
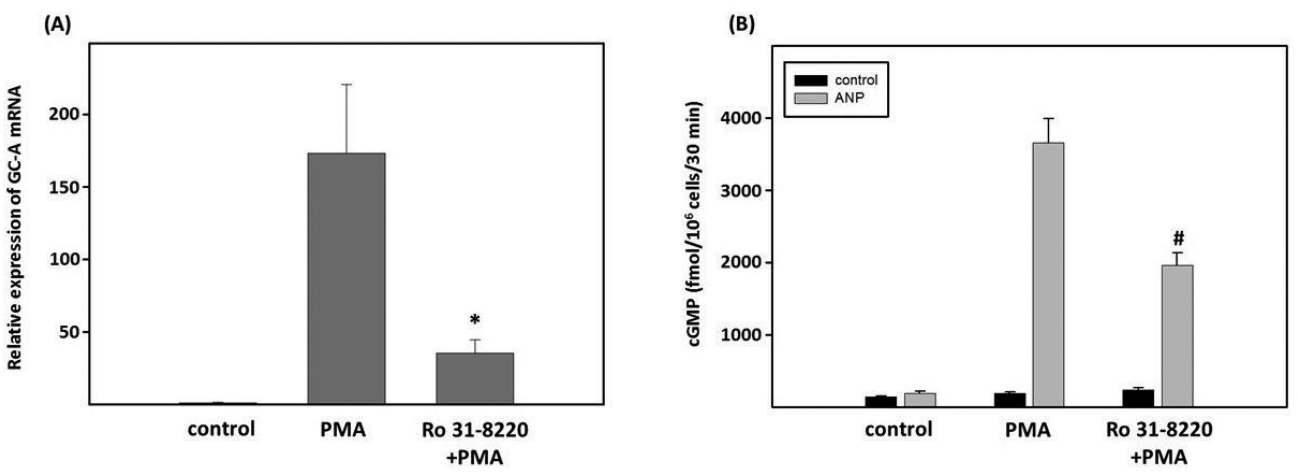

Figure 2. PKC mediates the PMA-induced expression of the gene encoding GC-A.

THP-1 cells were preincubated with $1 \mu \mathrm{M}$ Ro-318220 for 45 min and then treated with PMA for $72 \mathrm{~h}$. (A) Total RNA was isolated from the cells and the GC-A gene expression was determined using qPCR and was normalized to HPRT. (B) Cells were treated with 0.1 MM ANP for $30 \mathrm{~min}$ in the presence of $0.5 \mathrm{mM}$ IBMX. Then, intracellular cGMP was determined using ELISA. ${ }^{*} p<0.001$ versus PMA-treated cells, $\# p<0.01$ versus PMA-treated cells. 

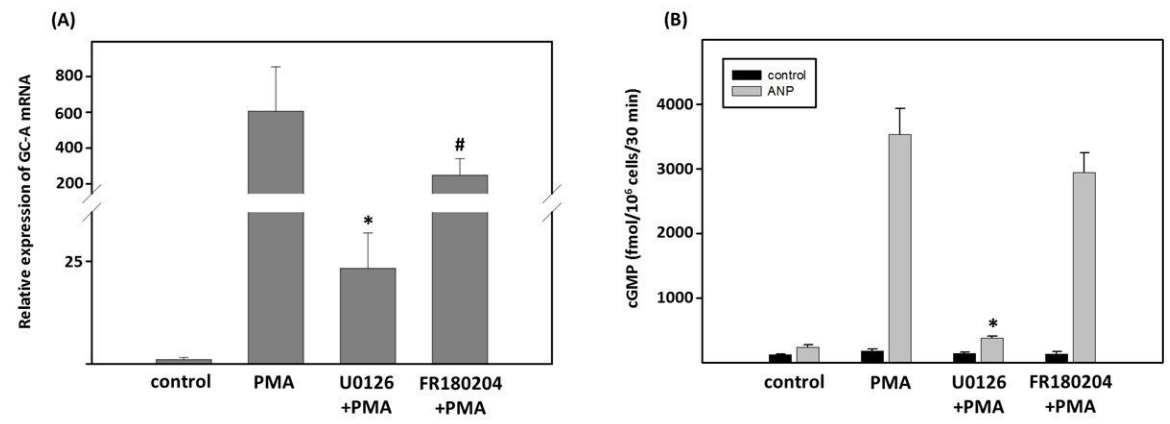

Figure 3. MEK1/2 and ERK $1 / 2$ are involved in the PMA-induced expression of GC-A.

THP-1 cells were preincubated with $10 \mu \mathrm{M}$ U0126 or $50 \mu \mathrm{M}$ FR180204 for 45 min and then treated with PMA for 72 h. (A) Total RNA was isolated from the cells and the GC-A gene expression was determined using qPCR and was normalized to HPRT. (B) Cells were treated with the $0.1 \mu \mathrm{M}$ ANP for $30 \mathrm{~min}$ in the presence of $0.5 \mathrm{mM}$ IBMX. Then, intracellular CGMP was determined using ELISA. ${ }^{*} p<0.001$ versus PMA-treated cells, $\# p<0.01$ versus PMA-treated cells.

\section{Sp1 transcription factor participates in regulation of the GC-A gene expression}

Sp1 is a ubiquitously expressed DNA-binding protein that can regulate transcription in response to physiological and pathophysiological stimuli. It has been shown that the Sp1 protein is implicated in regulation of various genes associated with different cellular processes. Therefore, as a first step, it was tested whether treat-
(A)

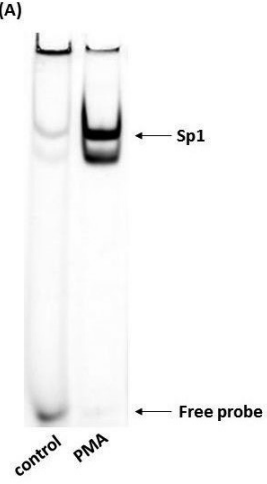

(B)
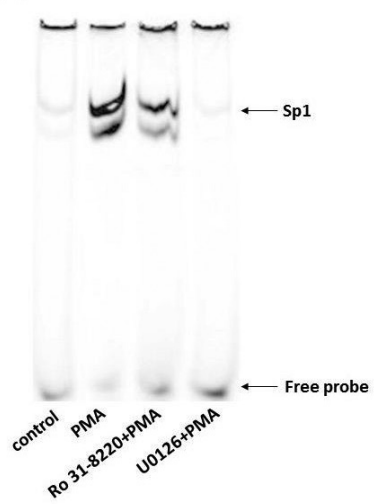

(c)

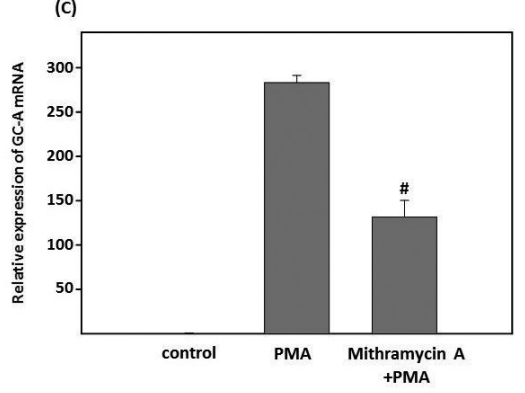

Figure 4. Sp1 mediates PMA-induced expression of the GC-A gene in THP-1 cells.

(A, B) THP-1 cells were treated with PMA in the absence or presence of specific inhibitors ( $1 \mu \mathrm{M}$ Ro $31-8220$ or $10 \mu \mathrm{M}$ U0126) and afterwards nuclear extracts were obtained, normalized for protein concentration and subjected to EMSA using oligonucleotides containing the Sp1 consensus binding site. (C) THP-1 cells were stimulated with PMA for $72 \mathrm{~h}$ in the absence or presence of Sp1 inhibitor (200 nM mithramycin A). Subsequently, total RNA was isolated from the cells and the GC-A gene expression was determined using qPCR and was normalized to HPRT. \#p<0.01 versus PMA-treated cells. ment of THP-1 cells with PMA resulted in an increase in DNA-binding activity to a synthetic double-stranded oligonucleotide containing the $\mathrm{Sp} 1$ consensus binding site. As shown by an EMSA method, the DNA-binding activity of Sp1 was barely detectable in control cells, but it increased markedly following the PMA treatment (Fig. 4A). The Sp1 protein is phosphorylated by various protein kinases, including PKC isoforms, ERK1/2 etc., at various sites within the protein (Chu, 2012). On the basis of our earlier results suggesting involvement of $\mathrm{PKC}$ and $\mathrm{MEK} 1 / 2$ in regulation of the GC-A expression, we examined the influence of PKC and MEK1/2 activities on DNA-binding activity of Sp1 in the PMAtreated cells. As shown by the EMSA method (Fig. 4B), the DNA-binding activity of Sp1 in PMA-treated cells was decreased in the presence of the PKC inhibitor, and was completely abolished in the presence of the MEK1/2 inhibitor. These findings support the hypothesis that in THP-1 cells both, PKC and MEK/ERKsignaling cassette, are involved in triggering the DNAbinding activity of Sp1 protein in response to PMA.

In the next step, in order to determine whether the PMA-induced GC-A gene expression requires DNAbound Sp1 molecules, the THP-1 cells were pretreated with mithramycin A, a known Sp1 inhibitor, before treatment with PMA. qPCR analysis revealed that mithramycin A considerably suppressed expression of GC-A mRNA in the PMA-treated cells (Fig. 4C). Compared to level of the GC-A gene expression in PMA-treated cells in the absence of an inhibitor, mithramycin A reduced the PMA-induced expression of the GC-A gene by about $50 \%$. Because mithramycin A binds to GC-rich DNA sequences, this result suggests that binding of Sp1 molecules to the $\mathrm{GC}$ boxes in the promoter region of the GC-A encoding gene is necessary for the PMA-induced GC-A gene expression in THP-1 cells.

\section{DISCUSSION}

Predominantly sGC was detected in human monocytes, but a large increase in the GC-A expression was observed in monocyte-derived macrophages (Bender et al., 2004). However, there is no data on factors and mechanisms that induce the GC-A expression in monocytes/macrophages. This raises questions about molecular mechanisms of activation of the GC-A gene in human monocytes/macrophages. Human monocytic cell line THP-1 was used as a model system for studying gene expression changes in PMA-induced differentiation 
into macrophage-like cells (Dieter \& Schwende, 2000). Here, by applying qPCR, Western blotting, and ELISA (Fig. 1), we found that the active form of GC-A receptor was produced in PMA-differentiated macrophagelike cells, but not in undifferentiated monocytic THP-1 cells, although few literature reports show the presence of GC-A in these cells (Glezeva et al., 2013; Mezzasoma et al., 2016). It is well known that activation of PKC by PMA triggers activation of the MEK/ERK-signaling cassette involved in transduction of extracellular stimuli to molecular networks responsible for differentiation and other cellular processes (Dieter \& Schwende, 2000; Miranda et al., 2002). Therefore, in order to determine whether these signaling molecules are involved in the observed induction of the GCA expression in THP1 cells, the specific inhibitors of PKC (Ro 31-8220), MEK1/2 (U0126), and ERK 1/2 (FR180204) were used. Results of our experiments showed that both, Ro 318220 and U0126, significantly reduced the PMA-induced up-regulation of the GCA gene expression (Figs. 2 and 3). The stimulatory effect of PMA on the GC-A mRNA expression was also inhibited by FR180204 (Fig. 3A). However, this reduction was weaker, although still statistically significant $(p<0.01)$. These results suggest that in THP-1 cells, both PKC and the MEK/ERK-signaling cassette are required for the PMA-induced GC-A expression. Presumably, PMA-activated PKC via phosphorylation of the Raf-1 protein kinase triggers the MEK/ERKdependent signaling cascade, leading to the increase in the GC-A gene expression.

Promoter region of the GC-A gene contains three potential Sp1-binding sites and their involvement in gene activation has been demonstrated (Liang et al., 1999; Garg et al., 2002). A few reports have shown that the $\mathrm{Sp} 1$ protein is involved in activation of the GC-A gene (Liang et al., 2001; Kumar et al., 2014). However, mechanisms of Sp1-mediated activation of the GC-A gene in different cell types remain unresolved. Based on these findings, we tested whether the observed up-regulation of the GC-A gene expression in PMA-treated THP-1 cells was also mediated by Sp1 protein. And indeed, our results show that $\mathrm{Sp} 1$ protein is involved in this process. Firstly, as shown by the EMSA method, the DNAbinding activity of Sp1 protein was markedly increased in the PMA-treated THP-1 cells (Fig. 4A). Moreover, the elevated activity of Sp1 protein in PMA-treated cells was markedly diminished in the presence of the PKC and MEK1/2 inhibitors (Fig. 4B), which also significantly reduced the PMA-mediated expression of GC-A (Figs. 2 and 3). Secondly, the inhibition of the DNA-binding activity of $\mathrm{Sp} 1$ protein had considerably decreased the GC-A expression in the PMA-treated cells (Fig. 4C). From these results we conclude that PMA stimulates the PKC/MAPK-dependent signaling cascade in THP-1 cells, which then triggers the DNA-binding activity of the Sp1 protein and subsequently leads to the upregulation of the GC-A gene expression.

Taking into account that mithramycin A did not completely, but by about $50 \%$, inhibit the PMA-induced GC-A gene expression (Fig. 4C), it is possible that other transcription factors are involved in the PMA-triggered GC-A expression. It was shown that the GC-A gene promoter region contains a CCAAT motif (Yamaguchi et al., 1990), which is recognized by the NF-Y transcription factor (Dolfini et al., 2012). Liang and co-workers (Liang et al., 2001) noted that in the rat aortic smooth muscle cells NF-Y is important for the GC-A gene transcription, because mutation of the CCAAT element significantly reduced activity of the GC-A promoter. Other investigators had shown that the GC-A gene was activated by retinoic acid-triggered transcriptional activator complex consisting of retinoic acid receptors, recruited by $\mathrm{Sp} 1$ and Ets-1 transcription factors to the promoter region of the GC-A gene (Kumar et al., 2010). Thus, it is possible that some other transcription factors cooperate with $\mathrm{Sp} 1$ protein in regulation of the PMA-triggered GC-A expression in THP-1 cells. Our unpublished data suggest that activity of NF-Y transcription factor is elevated in the PMA-treated THP-1 cells. However, more data are needed to confirm involvement of the NF-Y protein in the PMA-induced GC-A expression.

In summary, the data presented here support the report's conclusion that PMA-triggered activation of PKC followed by activation of the MEK/ERK-signaling cassette leads to Sp1-mediated expression of the GC-A encoding gene in human monocytic THP-1 cells.

\section{Conflict of interest}

The authors declare that they have no conflict of interest.

\section{Acknowledgements}

This work was supported by grant No. UMO2011/01/D/NZ3/04249 from the National Science Centre, Poland.

\section{REFERENCES}

Bender AT, Ostenson CL, Giordano D, Beavo JA (2004) Differentiation of human monocytes in vitro with granulocyte-macrophage colony-stimulating factor and macrophage colony-stimulating factor produces distinct changes in cGMP phosphodiesterase expression. Cell Signal 16: 365-374

Chu S (2012) Transcriptional regulation by post-transcriptional modification. Role of phosphorylation in Sp1 transcriptional activity. Gene 508: 1-8. doi: 10.1016/j.gene.2012.07.022

Dieter P, Schwende H (2000) Protein kinase C-alpha and -beta play antagonistic roles in the differentiation process of THP-1 cells. Cell Signal 12: 297-302

Dolfini D, Gatta R, Mantovani R (2012) NF-Y and the transcriptional activation of CCAAT promoters. Crit Rev Biochem Mol Biol 47: 29-49 doi: 10.3109/10409238.2011.628970

Garg R, Oliver PM, Maeda N, Pandey KN (2002) Genomic structure, organization, and promoter region analysis of murine guanylyl cyclase/atrial natriuretic peptide receptor-A gene. Gene 291: 123-133

Glezeva N, Collier P, Voon V, Ledwidge M, McDonald K, Watson C, Baugh J (2013) Attenuation of monocyte chemotaxis - a novel antiinflammatory mechanism of action for the cardio-protective hormone B-type natriuretic peptide. J Cardiovasc Transl Res 6: 545-557. doi: $10.1007 /$ s12265-013-9456-1

Kiemer AK, Hartung T, Vollmar AM (2000) cGMP-mediated inhibition of TNF- $\alpha$ production by the atrial natriuretic peptide in murine macrophages. I Immunol 165: 175-181

Kobiałka M, Witwicka H, Siednienko J, Gorczyca WA (2003) Metabolism of cyclic GMP in peritoneal macrophages of rat and guinea pig. Acta Biochim Pol 50: 837-848

Kumar P, Bolden GR, Pandey KN (2010) Interactive roles of Ets-1, $\mathrm{Sp} 1$, and acetylated histones in retinoic acid-dependent activation of guanylyl cyclase/atrial natriuretic peptide receptor-A gene transcription. I Biol Chem 285: 37521-37530. doi: 10.1074/jbc.M110.132795

Kumar P, Tripathi S, Pandey KN (2014) Histone deacetylase inhibitors modulate the transcriptional regulation of guanylyl cyclase/ natriuretic peptide receptor-a gene: interactive roles of modified histones, histone acetyltransferase, p300, and Sp1. J Biol Chem 289: 6991-7002. doi: 10.1074/jbc.M113.511444

Ladetzki-Baehs K, Keller M, Kiemer AK, Koch E, Zahler S, Wendel A, A.M. Vollmar AM (2007) Atrial natriuretic peptide, a regulator of nuclear factor- $x \mathrm{~B}$ activation in vivo. Endocrinology 148: 332-336

Liang F, Schaufele F, Gardner DG (2001) Functional interaction of $\mathrm{NF}-\mathrm{Y}$ and $\mathrm{Sp} 1$ is required for type a natriuretic peptide receptor gene transcription. J Biol Chem 276: 1516-1522

Liang F, Schaufele F, Gardner DG (1999) Sp1 dependence of natriuretic peptide receptor A gene transcription in rat aortic smooth muscle cells. Endocrinology 140: 1695-1701

Licata A, Corrao S, Petta S, Genco C, Cardillo M, Calvaruso V, Cabibbo G, Massenti F, Cammà C, Licata G, Craxì A (2013) NT proB- 
NP plasma level and atrial volume are linked to the severity of liver cirrhosis. PLoS One 8: e68364. doi: 10.1371/journal.pone.0068364

Livak KJ, Schmittgen TD (2001) Analysis of relative gene expression data using real-time quantitative PCR and the 2(-Delta Delta C(T)) Method. Methods 25: 402-408

Mezzasoma L, Antognelli C, Talesa VN (2016) Atrial natriuretic peptide down-regulates LPS/ATP-mediated IL-1 $\beta$ release by inhibiting NF- $\mathrm{kB}$, NLRP3 inflammasome and caspase-1 activation in THP-1 cells. Immunol Res 64: 303-312. doi: 10.1007/s12026-015-8751-0

Miranda MB, McGuire TF, Johnson DE (2002) Importance of MEK$1 /-2$ signaling in monocytic and granulocytic differentiation of myeloid cell lines. Leukemia 16: 683-692

Mitkiewicz M, Kuropatwa M, Kurowska E, Gorczyca WA (2011) Different effects of soluble and particulate guanylyl cyclases on expression of inflammatory cytokines in rat peripheral blood mononuclear cells. Immunobiology 216: 423-430. doi: 10.1016/j.imbio.2010.06.006

Morita R, Ukyo N, Furuya M, Uchiyama T, Horu T (2003) Atrial natriuretic peptide polarizes human dendritic cells toward a Th2-promoting phenotype through its receptor guanylyl cyclase-coupled receptor A. J Immunol 170: 5869-5875

Nojiri T, Hosoda H, Tokudome T, Miura K, Ishikane S, Kimura T, Shintani Y, Inoue M, Sawabata N, Miyazato M, Okumura M, Kangawa K (2014) Atrial natriuretic peptide inhibits lipopolysaccharide-induced acute lung injury. Pulm Pharmacol Ther 29: 24-30. doi: 10.1016/j.pupt.2014.01.003
Pandey KN (2011) The functional genomics of guanylyl cyclase/natriuretic peptide receptor-A: perspectives and paradigms. FEBS J 278: 1792-1807. doi: 10.1111/j.1742-4658.2011.08081.x

Pilz RB, Casteel DE (2003) Regulation of gene expression by cyclic GMP. Circ Res 93: 1034-1046

Potter LR, Abbey-Hosch S, Dickey DM (2006) Natriuretic peptides, their receptors, and cyclic guanosine monophosphate-dependent signaling functions. Endocr Rev 27: 47-72

Su J, Scholz PM, Weiss HR (2005) Differential effects of cGMP produced by soluble and particulate guanylyl cyclase on mouse ventricular myocytes. Exp Biol Med 230: 242-250

Szabó T, Postrach E, Mähler A, Kung T, Turhan G, von Haehling S, Anker SD, Boschmann M, Doehner W (2013) Increased catabolic activity in adipose tissue of patients with chronic heart failure. Eur J Heart Fail 15: 1131-1137. doi: 10.1093/eurjhf/hft067

Yamaguchi M, Rutledge LJ, Garbers DL (1990) The primary structure of the rat guanylyl cyclase A/atrial natriuretic peptide receptor gene. J Biol Chem 265: 20414-20420

Zolle O, Lawrie AM, Simpson AW (2000) Activation of the particulate and not the soluble guanylate cyclase leads to the inhibition of $\mathrm{Ca}^{2+}$ extrusion through localized elevation of cGMP. J Biol Chem 275: 25892-25899 